\title{
Research on the control of slack flow of China-Kazakhstan crude oil pipeline
}

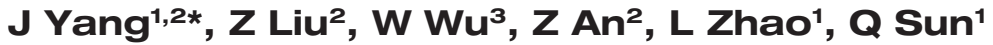 \\ 1. Northeast Petroleum University, Daqing, China \\ 2. Sino-pipeline International Company, Beijing, China \\ 3. Exploration and Development Research Institute of \\ PetroChina Jilin Oilfield Co. Ltd., SongYuan, China
}

\begin{abstract}
China-Kazakhstan pipeline is the first land import transnational crude oil pipeline in China. It is also the only long-distance crude oil channel connecting the resources in the west of Kazakhstan and the two refineries in the east of Kazakhstan and exports to China. It undertakes the dual responsibilities of crude oil supply of the two refineries in the east of Kazakhstan and the crude oil guarantee of refineries in Western China. At present, the annual throughput of China-Kazakhstan crude oil pipeline accounts for about $20 \%$ of China's onshore crude oil imports. Therefore, the pipeline's safe, stable and efficient operation plays an important role in ensuring the strategic security of energy in Western China. Since the ChinaKazakhstan crude oil pipeline has commissioned, it has been found that there is slack flow in the pipeline under different working conditions, which has a great impact on the safe and stable operation of the pipeline and the measurement accuracy of commercial trade. In this paper, the causes of slack flow in China-Kazakhstan crude oil pipeline are studied, the potential location of slack flow is analyzed, and the boundary conditions of slack flow condition are defined. At the same time, control strategies to avoid slack flow under different conditions are formulated by using simulation technology. The research results will provide direct technical case support for reasonable formulation of operation scheme of China-Kazakhstan crude oil pipeline system and terminal station inlet pressure control strategy, so as to ensure safe, stable and efficient operation of the pipeline.
\end{abstract}

\section{INTRODUCTION}

The China-Kazakhstan crude oil pipeline starts from Atyrau in the west of Kazakhstan, passes through Kenkiyak, Kumkol and Atasu, and ends at the oil pipeline of Alashankou metering station in Xinjiang, China. In 2015, after the flowmeter of Alashankou, the terminal station of China-Kazakhstan crude oil pipeline, was replaced from volumetric one into mass one, the positive transmission error of the whole line was reduced. Through research and analysis, the reason for the decrease of positive transmission error was that near the Alashankou high point, the phenomenon of slack flow was caused after the upstream pump stopped, resulting in foaming in the pipeline, which led to the measurement value of the volumetric flowmeter being relatively high. 
The long-term existence of slack flow condition will cause erosion to the pipeline and affect its safe operation. Therefore, it is necessary to carry out transiently simulated hydraulic calculation for pipeline operation under different conditions and formulate the control strategy of slack flow. The following problems were found in the research process:

(1) The whole pipeline of China-Kazakhstan crude oil pipeline has the characteristics of complex oil source composition and great difference in physical properties of different oil sources. Therefore, the physical properties of actual pipeline oil are uncertain.

(2) The simulation accuracy is not high, and the setting of parameters and simulation calculation of simulation system in the design and operation stages has not really reflected the pipeline state. During the actual operation of China-Kazakhstan pipeline, it is found that the actual operation characteristics of pump units deviate greatly from the performance curve promised or provided by the manufacturer, and the relative errors are mostly between $5 \%$ and $15 \%$. Therefore, the operators cannot master the actual energy efficiency status of the units, which will affect the accuracy of the operation scheme formulation and the accuracy of emergency rescue decision.

(3) It is necessary to establish an accurate simulation model before to formulate an accurate control strategy of slack flow, so that the research conclusions can be applied to the actual operation.

In order to solve above problems effectively, the following contents are studied:

(1) During the period from October 19 to 24, 2019, crude oil samples were taken at Alashankou metering station at the end of the pipeline and physical property tests were carried out. According to ISO3170, $400 \mathrm{ml}$ crude oil was sampled manually for 6 days and every 2 hours. A total of $4800 \mathrm{ml} * 6$ crude oil samples were completed. The physical properties of oil samples from the pipeline was confirmed by test. On this basis, the study was carried out.

(2) Study and formulate the calibration method of pump performance curve and complete the curve correction. By optimizing the equation fitting the pump factory characteristics, the head-flow characteristic parameters and efficiency-flow characteristic parameter curves of the pump are fitted, and 24 pumps in the whole line are fitted; the calibration method of factory characteristic curve of oil pump is studied, and the pump performance curve is corrected by screening the steady-state historical operation data, and the pump performance calculation and curve data automatic correction software are developed to ensure the simulation accuracy deviation from the actual value is less than $3 \%$;

(3) The whole line simulation model is established. According to the actual operation situation of the whole line, the hydraulic and thermal calculation model of the pipeline is established by using the SPS simulation system, and the hydraulic and thermal adjustment is carried out by using the field data, so that the relative error between the simulation result and the actual operation is within $3 \%$.

(4) The method to determine the crossing point of pipeline transportation and the pipeline section where slack flow could happen is put forward, based on which the inlet pressure control strategy of Alashankou under different throughput steps is formulated to avoid the generation of high point slack flow. 
Through the above research, the simulation accuracy higher than 95\% is achieved, and the reliability of scheme decision-making is improved. At the same time, the control strategy of slack flow of China-Kazakhstan crude oil pipeline is proposed by using transient simulation technology to ensure the safe operation of the pipeline and the measurement accuracy reaches the standard.

\section{OIL PHYSICAL PROPERTY TEST}

The whole pipeline of China-Kazakhstan crude oil pipeline has the characteristics of complex oil source composition and great difference in physical properties of different oil sources. Therefore, the physical properties of actual pipeline oil are uncertain. Crude oil was sampled and physical properties were tested at Alashankou metering station at the end of the pipeline from October 19 to 24, 2019. According to ISO3170, 400ml crude oil was sampled manually every 2 hours for 6 days. A total of $4800 \mathrm{ml} * 6$ crude oil samples were completed. The crude oil samples were divided into two groups for testing, and the density, viscosity and viscositytemperature curve, abnormal point, condensation point, wax precipitation point, wax content, wax precipitation at different temperatures, gel content, asphaltene content, water content and specific heat capacity of the two groups were tested respectively. Because the density and viscosity of oil properties have great influence on this study, this chapter only introduces the test method and conclusion of density and viscosity of crude oil in detail [1-2].

\subsection{Test execution standard and referred method}

- SH/T 0604-2000: Determination of density of crude oil and petroleum products (Ushaped vibrating tube method)

- SY/T 0520-2008: Determination of crude oil viscosity by rotating viscometer balance method

- SY/T 0541-2009: Determination of crude oil pour point

- SY/T 7550-2012: Determination of wax, gel and asphaltene in crude oil

- SY/T 0545-2012: Determination of characteristic parameters of wax precipitation in crude oil by differential scanning calorimetry

- NB/SH/T 0632-2014: Determination of specific heat capacity by differential scanning calorimetry

- GB/T 8929-2006: Determination of water content in crude oil (distillation method) 


\subsection{Crude oil density test}

The density of oil was measured by U-shaped vibrating tube method. A small amount of sample (generally less than $1 \mathrm{~mL}$ ) is injected into the sample tube with controlled temperature. The vibration frequency or period is recorded, and the density of the sample is calculated with the obtained tube constant. The constant of the sample tube is determined by the vibration frequency when the sample tube is filled with the calibration solution of known density. The density of the two oil products is obtained through the test as shown in Table 1.

Table 1. Oil density test data

\begin{tabular}{ll}
\hline Oil number & Density $\left(\mathbf{2 0}{ }^{\circ} \mathbf{C}\right), \mathbf{g} / \mathbf{c m}^{\mathbf{3}}$ \\
\hline M-2019-1021 & 0.8577 \\
M-2019-1022 & 0.8575 \\
\hline
\end{tabular}

\subsection{Oil viscosity test}

The viscosity of oil was measured by rotating viscometer balance method. The principle of this method is to make the surrounding fluid flow stably layer by layer by rotating the cylinder. The viscous torque of the fluid will act on the cylinder. The relationship between the viscosity and torque of the fluid can be expressed by formula (1) [3-5],

$$
\eta=\frac{K \cdot M}{\omega}
$$

where:

$\eta$ - The viscosity of a fluid, in paseconds $(\mathrm{Pa} \cdot \mathrm{s})$;

$M$ - Viscous torque of fluid acting on cylinder, in $\mathrm{NM}(\mathrm{N} \cdot \mathrm{m})$;

$\omega$ - The rotational speed of the cylinder, in radians per second ( $\mathrm{rad} / \mathrm{s})$;

$K$ - Flow field constant, unit: negative cubic meter (m-3).

According to the relationship between $\mathrm{M}$ and $\tau, \omega$ and $\dot{\gamma}$, the shear stress $\gamma$ on the cylindrical flow layer is expressed by formula (2), and the viscosity or apparent viscosity is calculated by formula (3) (for non-Newtonian fluid, $\eta$ should be the apparent viscosity $\eta s$ ).

$$
\begin{gathered}
\tau=Z \cdot a \\
\eta=\frac{\tau}{\dot{\gamma}}
\end{gathered}
$$

where:

$\gamma$ - Shear stress in Pascal $(\mathrm{Pa})$;

$Z$ - The instrument measures the system constant in Pascal (Pa);

$a$ - Instrument indication;

$\dot{\gamma}$ - Shear rate, in negative power second $\left(\mathrm{s}^{-1}\right)$ 
Table 2: Oil viscosity test data

\begin{tabular}{ll}
\hline Oil Number & Viscosity $\left(25^{\circ} \mathbf{C}\right), \mathbf{m P a} \cdot \mathbf{s}$ \\
\hline $\mathrm{M}-2019-1021$ & 7.14 \\
$\mathrm{M}-2019-1022$ & 7.35 \\
\hline
\end{tabular}

The viscosity-temperature characteristic curves of the two oils are shown in Fig. 1 and Fig. 2.

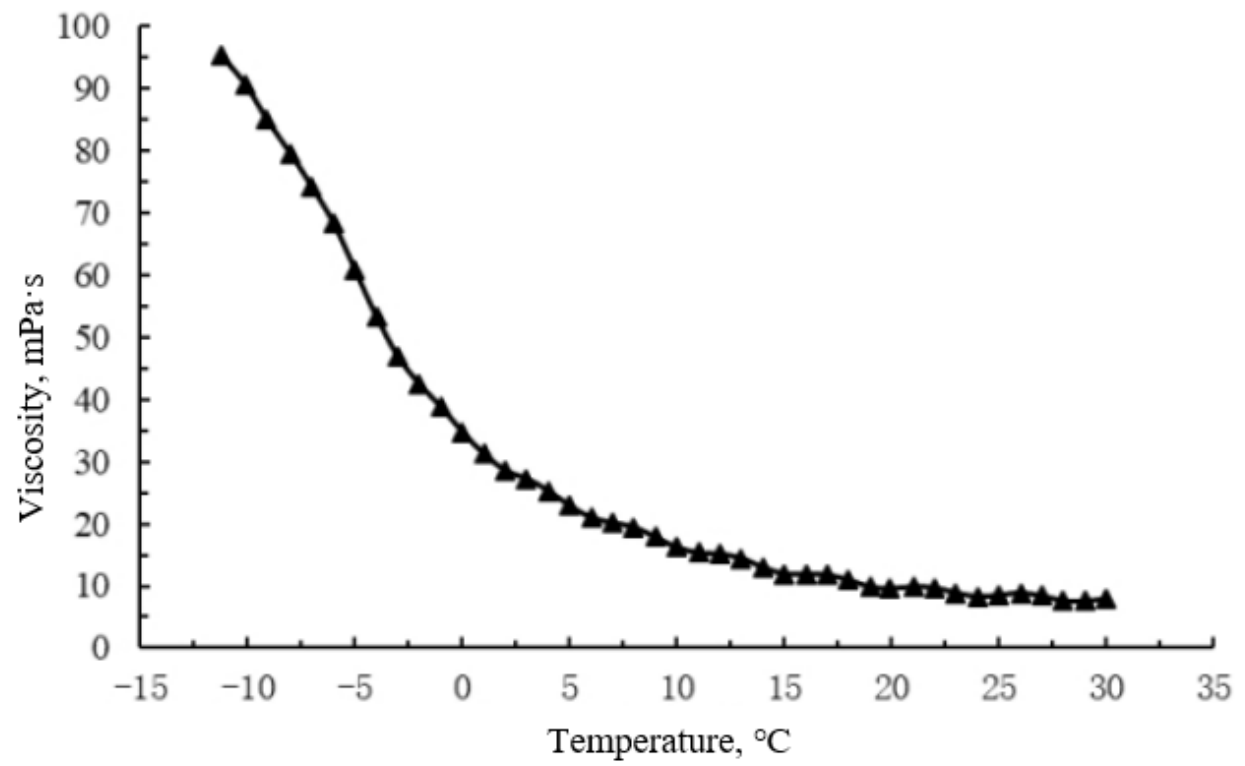

Figure 1. Viscosity-temperature characteristic curve of M-2019-1021 oil 


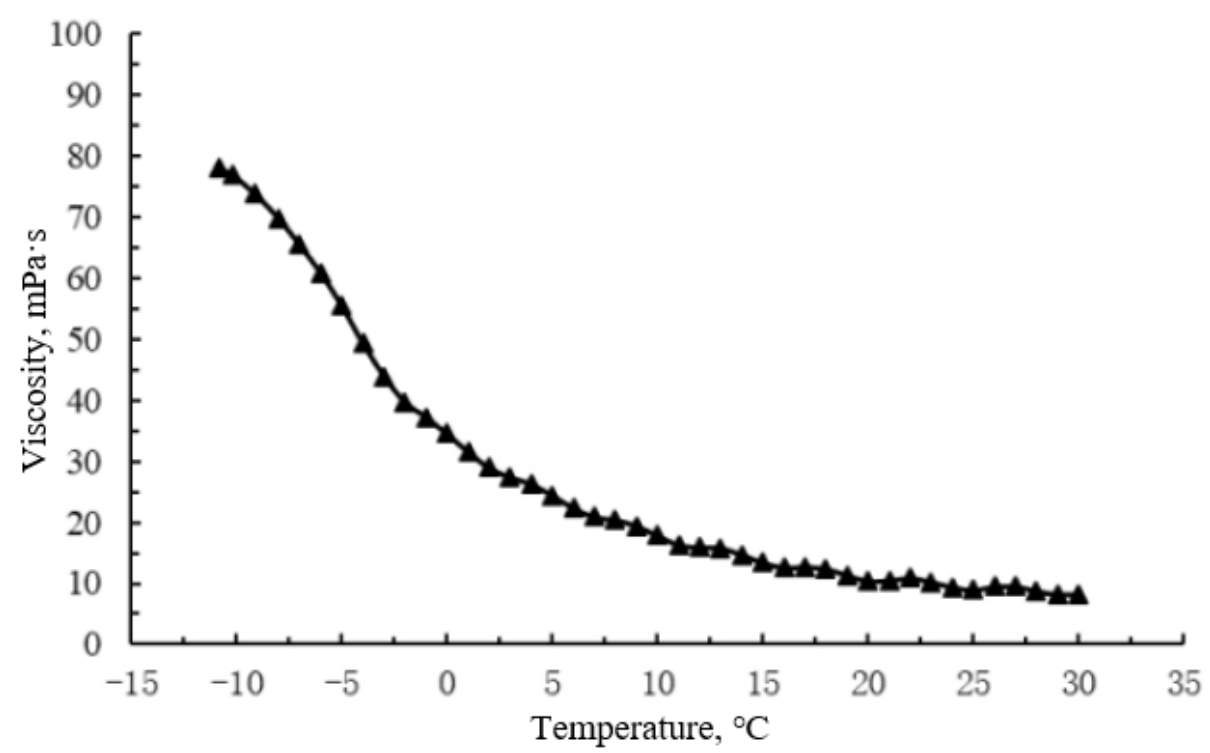

Figure 2. Viscosity temperature characteristic curve of M-2019-1022 oil

\subsection{Conclusion of physical property test}

The test results show that the oil has good physical properties and can meet the transportation requirements at normal temperature. The following studies are based on the physical properties of the oil. The test results of oil products are shown in Tables 3 and 4 [6-7].

Table 3. Oil test data

\begin{tabular}{lll}
\hline Test indicators & $\begin{array}{l}\text { M-2019-1021 oil test } \\
\text { results }\end{array}$ & $\begin{array}{l}\text { M-2019-1022 oil test } \\
\text { results }\end{array}$ \\
\hline Density $\left(20{ }^{\circ} \mathrm{C}\right), \mathrm{g} / \mathrm{cm}^{3}$ & 0.8572 & 0.8569 \\
Viscosity $\left(25^{\circ} \mathrm{C}\right), \mathrm{MPa} \cdot \mathrm{s}$ & 8.26 & 7.97 \\
Abnormal point, ${ }^{\circ} \mathrm{C}$ & 2.0 & 1.8 \\
Freezing point, ${ }^{\circ} \mathrm{C}$ & -10.5 & -11.5 \\
Wax precipitation point, ${ }^{\circ} \mathrm{C}$ & 18.6 & 18.7 \\
Wax content, \%, at $~\left(-40{ }^{\circ} \mathrm{C}\right)$ & 3.68 & 3.24 \\
Gel content, \% & 1.09 & 1.15 \\
Asphaltene content, $\%$ & 0.54 & 0.60 \\
Water content, \% & 0.162 & 0.092 \\
Specific heat capacity $\left(25{ }^{\circ} \mathrm{C}\right), \mathrm{J} / \mathrm{g} \cdot{ }^{\circ} \mathrm{C}$ & 2.464 & 2.490 \\
\hline
\end{tabular}


Table 4. Kinematic Viscosity test data

\begin{tabular}{lll}
\hline Temperatures $\left({ }^{\circ} \mathrm{C}\right)$ & \multicolumn{2}{c}{ Test result, mPa.s } \\
& M-2019-1021 & M-2019-1022 \\
\hline$-10^{\circ} \mathrm{C}$ & 90.70 & 71.16 \\
$-5^{\circ} \mathrm{C}$ & 60.81 & 50.96 \\
$0^{\circ} \mathrm{C}$ & 34.77 & 32.69 \\
$5^{\circ} \mathrm{C}$ & 22.89 & 23.62 \\
$10^{\circ} \mathrm{C}$ & 16.15 & 17.85 \\
$15^{\circ} \mathrm{C}$ & 11.94 & 13.85 \\
$20^{\circ} \mathrm{C}$ & 9.60 & 11.15 \\
\hline
\end{tabular}

\section{CALIBRATE SIMULATION MODEL}

The hydraulic and thermal calculation model of the pipeline is established by using SPS simulation system, and the model is checked hydraulically and thermally by field data. The relative error between the simulation result and the actual operation is within $3 \%$;

Pump characteristic curve is not only the basis for calculating pump performance, but also the theoretical basis for reflecting its performance. Combined with the actual situation of China-Kazakhstan crude oil pipeline, through the research on the existing pump characteristic curve of the whole line, it is found that the actual operation characteristics of the pump deviate greatly from the performance curve provided by the manufacturer, which results in the discrepancy between the simulation calculation results and the actual situation, which affects the formulation of the optimal pump startup scheme of the whole line and the accuracy of emergency decision-making. Therefore, it is necessary to correct the performance curve of oil pump to improve the accuracy of normal and emergency operation plan. The calibration of pump characteristic curve is the most important part of the simulation model calibration. In this chapter, the calibration method is discussed in detail [8-10].

\subsection{Data screening}

In this paper, from the operation data of China-Kazakhstan crude oil pipeline for years, the operation data with wide operation range, which can better reflect the difference between the actual characteristics and the factory characteristics of the oil pump, is selected to correct the pump characteristic curve. All the screened data were divided into two parts, $60 \%$ of which were used to calculate the correction value of pump characteristics, and the remaining part was used for verification. [11-12].

In order to ensure that the accuracy of pump characteristic curve is higher than $97 \%$, interval optimization method is used in this paper, that is, according to the characteristics of most operation data and referring to the sample indexes including absolute error of pump head and pump efficiency, the data points beyond a certain range are considered as potential error points and are eliminated. The advantage of this method is that it is simple and easy to operate, at the same time, it can ensure the quality of data and avoid the omission of wrong data or excessive elimination of correct data. 
The interval optimization method first calculates the actual head and efficiency of the pump according to the actual operation data, and calculates the average error value (formula 4) by comparing the head and efficiency under the same throughput corresponding to the factory performance curve.

$$
\operatorname{Err}=\frac{\sum_{i=1}^{N}\left[\frac{\mid p r o}{\text { pro }- \text { pro } \mid}\right]}{N}
$$

where:

Err - Average error.

pro' - Actual characteristics of pump.

pro - The pump characteristics calculated according to the characteristic curve provided by the manufacturer, referred to as "factory characteristic parameters".

According to formula 4, the average error of the actual operation characteristics and factory characteristics of the pump under different conditions is calculated, and then the average error of $\mathrm{N}$ groups of data is obtained through the formula, and the average error line is drawn to form the average error curve. The points on the average error line are the data \pm average error corresponding to the output performance curve under different flow rates (public notice 5).

$$
H=A-B Q^{2-m}+\text { Error }
$$

where:

$H$ - Head corresponding to average error line;

$Q$ - Actual flow;

Error - Average error.

The average error line * $(1 \pm 5 \%)$ defines two blue floating lines $\mathrm{A}$ and $\mathrm{C}$, and the data points outside the floating line range will be eliminated (as shown in Figure 3). 


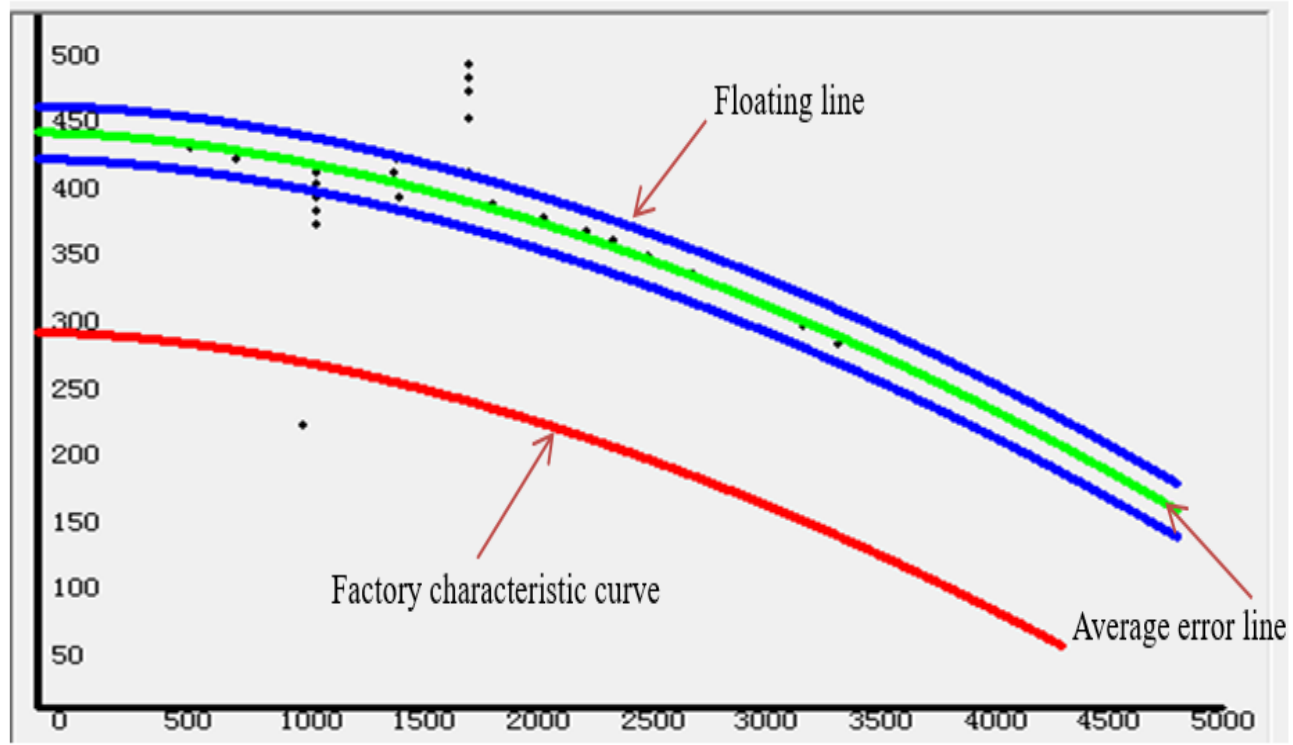

Figure 3. Interval optimization method

Taking No.1 pump on site as an example, the specific steps are as follows:

Float the factory performance curve downward, and the point on the floating curve = the point on the factory performance curve * (1-5\%).

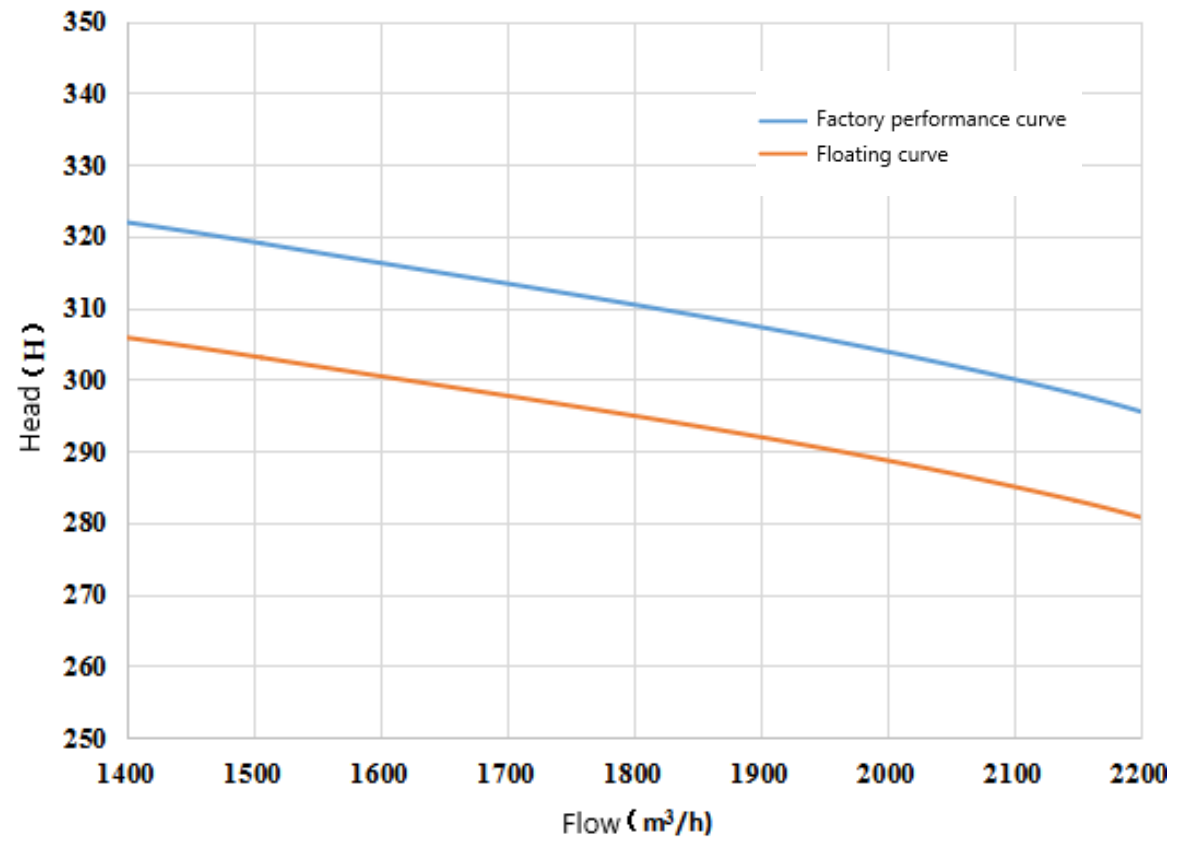

Figure 4. Floating curve 
The field data sheet is arranged as follows:

Table 5. Arranged field data

\begin{tabular}{|c|c|c|c|c|c|}
\hline Number & Flow $\left(\mathbf{m}^{3} / \mathbf{h}\right)$ & Head(H) & Number & Flow $\left(\mathbf{m}^{3} / \mathbf{h}\right)$ & Head(H) \\
\hline 1 & 1813.68 & 301.12 & 43 & 1703.82 & 301.72 \\
\hline 2 & 1715.59 & 305.92 & 44 & 1707.40 & 304.12 \\
\hline 3 & 1663.53 & 307.12 & 45 & 1696.76 & 298.12 \\
\hline 4 & 1654.22 & 305.92 & 46 & 1721.57 & 302.92 \\
\hline 5 & 1670.83 & 302.32 & 47 & 1720.98 & 298.12 \\
\hline 6 & 1677.06 & 305.92 & 48 & 1726.03 & 296.92 \\
\hline 7 & 1527.99 & 308.33 & 49 & 1718.43 & 304.12 \\
\hline 8 & 1642.60 & 304.72 & 50 & 1709.66 & 304.12 \\
\hline 9 & 1635.98 & 304.72 & 51 & 1689.71 & 305.32 \\
\hline 10 & 1641.72 & 297.52 & 52 & 1703.33 & 299.32 \\
\hline 11 & 1737.60 & 291.52 & 53 & 1702.55 & 302.92 \\
\hline 12 & 1791.42 & 298.72 & 54 & 1707.11 & 312.53 \\
\hline 13 & 1802.50 & 299.92 & 55 & 1689.17 & 304.12 \\
\hline 14 & 1802.40 & 301.12 & 56 & 1714.41 & 304.12 \\
\hline 15 & 1798.04 & 301.12 & 57 & 1845.15 & 304.12 \\
\hline 16 & 1774.41 & 301.12 & 58 & 1847.35 & 301.72 \\
\hline 17 & 1794.26 & 297.52 & 59 & 1851.18 & 299.32 \\
\hline 18 & 1799.31 & 304.72 & 60 & 1850.44 & 300.52 \\
\hline 19 & 1796.76 & 302.32 & 61 & 1723.33 & 300.52 \\
\hline 20 & 1794.90 & 298.72 & 62 & 1685.10 & 306.52 \\
\hline 21 & 1779.90 & 302.32 & 63 & 1673.77 & 306.52 \\
\hline 22 & 1785.83 & 299.92 & 64 & 1689.31 & 305.32 \\
\hline 23 & 1791.23 & 301.12 & 65 & 1674.17 & 299.32 \\
\hline 24 & 1786.52 & 302.32 & 66 & 1737.60 & 307.72 \\
\hline 25 & 1780.69 & 302.32 & 67 & 1791.42 & 307.72 \\
\hline 26 & 1789.41 & 299.92 & 68 & 1802.50 & 308.92 \\
\hline 27 & 1789.75 & 301.12 & 69 & 1802.40 & 301.72 \\
\hline 28 & 1788.24 & 302.32 & 70 & 1798.04 & 304.12 \\
\hline 29 & 1783.09 & 303.52 & 71 & 1774.41 & 307.72 \\
\hline 30 & 1665.98 & 303.52 & 72 & 1794.26 & 301.72 \\
\hline 31 & 1728.14 & 299.32 & 73 & 1799.31 & 302.92 \\
\hline 32 & 1723.24 & 299.32 & 74 & 1796.76 & 300.52 \\
\hline 33 & 1734.80 & 305.32 & 75 & 1794.90 & 307.72 \\
\hline 34 & 1702.75 & 304.12 & 76 & 1779.90 & 306.52 \\
\hline 35 & 1697.84 & 304.12 & 77 & 1785.83 & 308.92 \\
\hline 36 & 1730.34 & 305.32 & 78 & 1791.23 & 308.92 \\
\hline 37 & 1734.17 & 299.32 & 79 & 1786.52 & 308.92 \\
\hline 38 & 1729.17 & 304.12 & 80 & 1780.69 & 305.32 \\
\hline 39 & 1717.84 & 306.52 & 81 & 1789.41 & 311.33 \\
\hline 40 & 1736.52 & 310.12 & 82 & 1789.75 & 311.33 \\
\hline 41 & 1744.07 & 304.12 & 83 & 1788.24 & 308.92 \\
\hline 42 & 1718.58 & 304.12 & 84 & 1783.09 & 308.92 \\
\hline
\end{tabular}


The arranged data are drawn into a graph. The points outside the floating curve shown in Figure 5 are outliers, which are considered as potential error points and are eliminated [13$16]$.

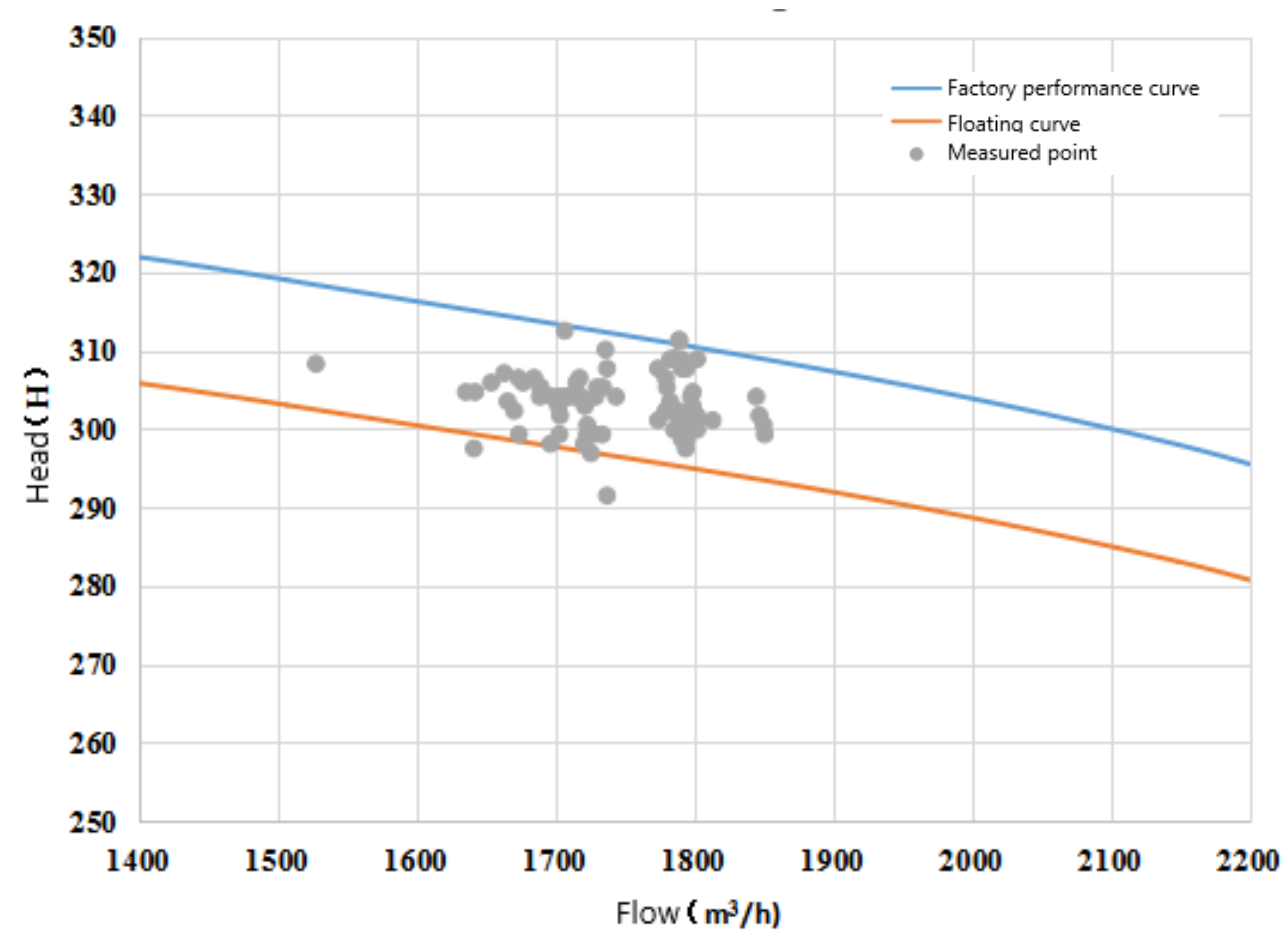

Figure 5 Interval optimization method

\subsection{Optimal characteristic curve equation}

The head performance and efficiency performance curve of the pump respectively represent the head and efficiency corresponding to different flow under the same speed condition. Therefore, the relationship between the two is fitted into an algebraic equation instead of looking up the diagram to calculate the head and efficiency under the fixed flow more conveniently and realize the dynamic measurement of the pump unit characteristics.

By studying the head-flow curve of the pump, two expression forms of head characteristic curves are determined, as shown in (6) and (7). Formula (8) is the physical meaning expression of pump head [17-18],

$$
\begin{gathered}
H=A-B Q^{2-m} \\
H=a_{0}+a_{1} Q+a_{2} Q^{2} \\
H=\frac{\left(P_{B}-P_{A}\right) \times 10^{6}}{\rho g}+\left(H_{B}-H_{A}\right)+\frac{c_{B}^{2}-c_{A}^{2}}{2 g}
\end{gathered}
$$


where:

$A, B$ - The constant determined by the least square method;

$Q$ - Pipe flow, $\mathrm{m}^{3} / \mathrm{h}$;

$c_{A}, c_{B}$ - Average velocity of liquid at pump inlet and outlet, $\mathrm{m} / \mathrm{s}$;

$m$ - Flow pattern index, laminar flow $M=1$, hydraulic smooth zone $M=0.25$, mixed

friction zone $M=0.123$, rough zone $M=0$;

$p_{A}$ - Pump inlet pressure, MPa;

$p_{B}$ - Pump outlet pressure, MPa;

$H_{A}$ - Height of oil pump inlet pressure gauge based on ground, m;

$H_{B}$ - Height of oil pump outlet pressure gauge based on ground, m.

Through a large number of data calculation and comparison, the error between formula (6) and field data is small. And formula (6) takes into account the fluid flow pattern. As we all know, the fluid flow pattern in the pipeline plays an important role in the temperature and pressure drop of the pipeline. To sum up, the head flow equation is in the form of formula (6). Since the distances from the actual pump inlet and outlet liquid level to the pump shaft center are the same, equation (6) can be written as equation (9). Figure 3. shows the head flow characteristic curve of constant speed pump:

$$
H=A-B Q^{2-m}=\frac{p_{B}-p_{A}}{\rho g}+\frac{c_{B}^{2}-c_{A}^{2}}{2 g}
$$

For two pumps with the same geometric dimensions or the same pump, when the speed changes from $n_{1}$ to $n_{2}$, according to the law of similarity, there are (the parameters of $n_{1}$ and $n_{2}$ are represented by subscripts 1 and 2 respectively):

$$
\frac{Q_{1}}{Q_{2}}=\frac{n_{1}}{n_{2}} \quad \frac{H_{1}}{H_{2}}=\left(\frac{n_{1}}{n_{2}}\right)^{2}
$$

According to the above proportional formula, given the relevant parameters at $n_{1}$ speed, the head-flow equation of speed $n_{2}$ is as follows:

$$
H=A-B\left(\frac{Q_{1} n_{2}}{n_{1}}\right)^{2-m}=\left(\frac{p_{B}-p_{A}}{\rho g}+\frac{c_{B}^{2}-c_{A}^{2}}{2 g}\right) \times\left(\frac{n_{2}}{n_{1}}\right)^{2}
$$

According to the above equation, the head of the same or similar pump will change when the speed changes. Figure 4 shows the head flow curve at different speeds [19-20]. 


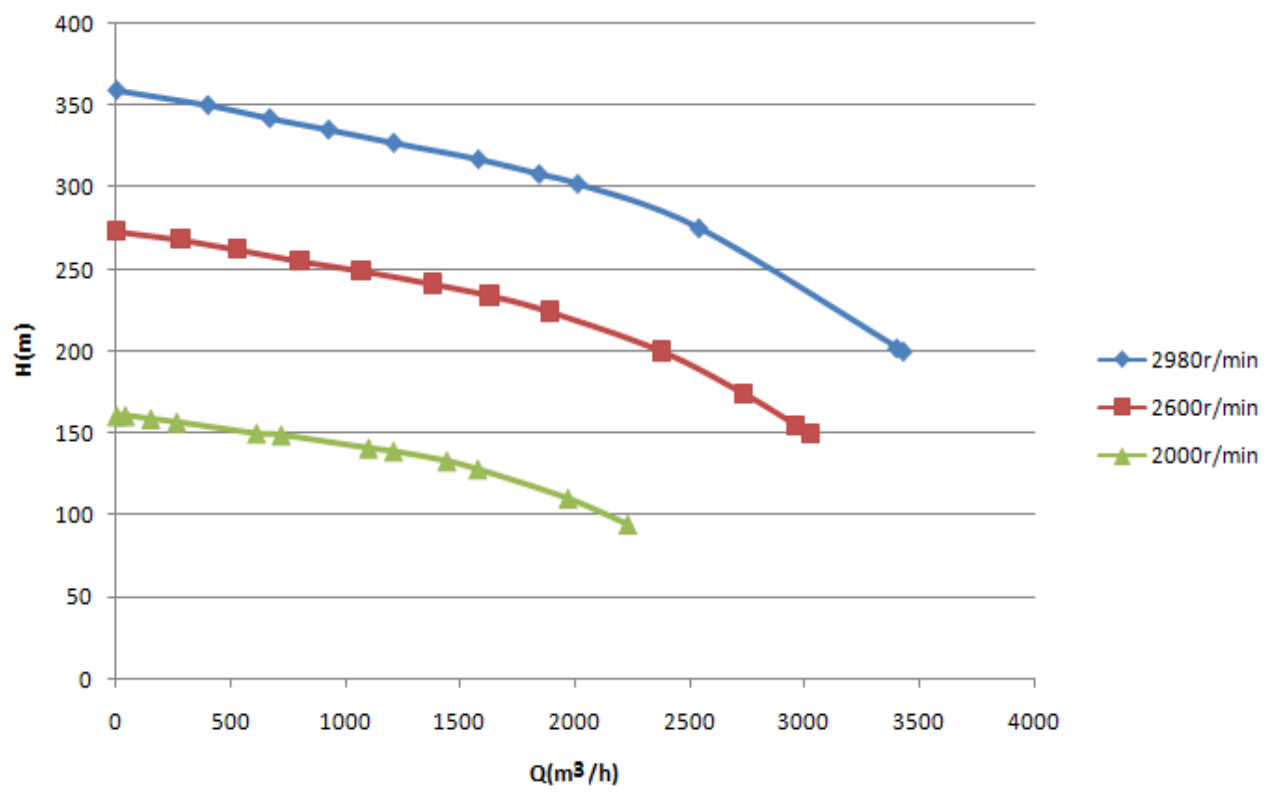

Figure 6. Head-flow characteristic curve under variable speed

\subsection{Correction method of characteristic curve}

The data for calculating the correction value of characteristic curve mainly selects the actual data of field from February 2018 to June 2019. The operation is relatively stable, the data is comprehensive and of high quality during this period, which can better reflect the difference between the actual characteristics of the equipment and the factory characteristics. In this study, the selected data were divided into two parts, $70 \%$ of which were used to calculate the correction value of pump characteristics, and the remaining part was used for verification.

The basic idea of the correction of pump characteristic curve is image translation method, that is, the actual characteristic parameters are best approximated by moving the factory characteristic curve, so two correction quantities $\mathrm{X}$ and $\mathrm{Y}$ are introduced.

Taking the head-performance curve as an example, the original head curve of the headperformance curve is assumed to be:

$$
H=a-b Q^{1.75}
$$

By moving $\mathrm{X}$ and $\mathrm{Y}$ units along the positive direction of the two coordinate axes, the head curve can be as close as possible to the head characteristics reflected by the actual operation data. The head curve after moving is as follows:

$$
H=a-b(Q-x)^{1.75}+y
$$


The solution of correction quantity $\mathrm{X}$ and $\mathrm{Y}$ is the least square problem: if there are $\mathrm{N}$ groups of pumping station's head data points, $\mathrm{X}$ and $\mathrm{Y}$ need to be determined to satisfy (13) [21-25],

$$
f(x, y)=\min \sum_{i=1}^{N}\left[a-b^{*}\left(Q_{i}-x\right)^{1.75}+y-H_{i}\right]^{2}
$$

\subsection{Correction of pump characteristic curve}

A total of 47 data points are used to correct the head-flow curve of No.1 pump. Select $70 \%$ to correct, that is, 33 data to correct, the remaining 14 data to verify. The relative error of No.1 pump is 0.03 . The corrected head-flow equation is as follows:

$$
H=266.126-7.94 \times 10^{-5} \times Q^{1.75}-13
$$

The comparison of error distribution before and after correction is shown in Table 6, and the correction meets the requirements.

Table 6. Error comparison

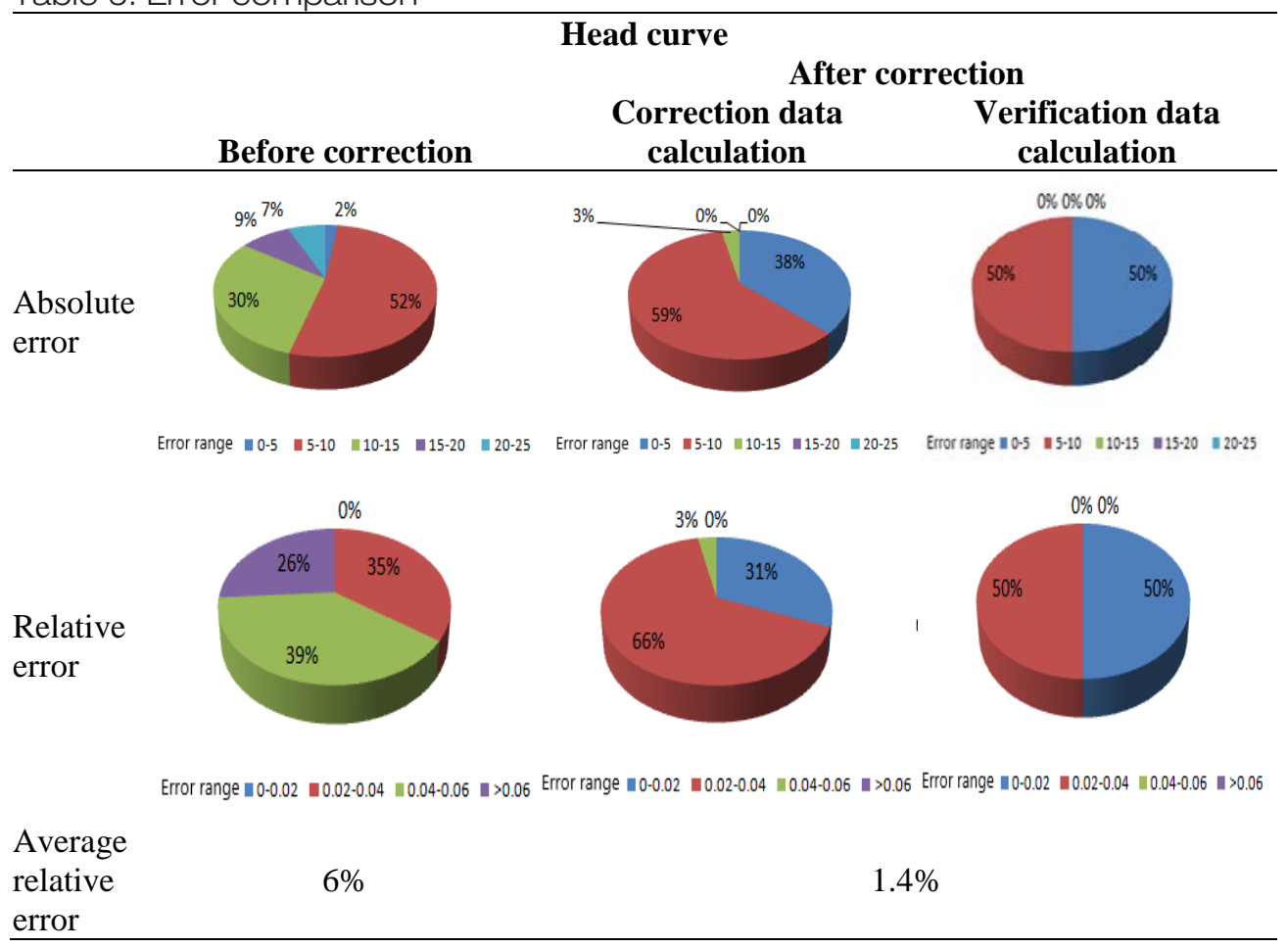


The following curve is drawn through the data before and after correction:

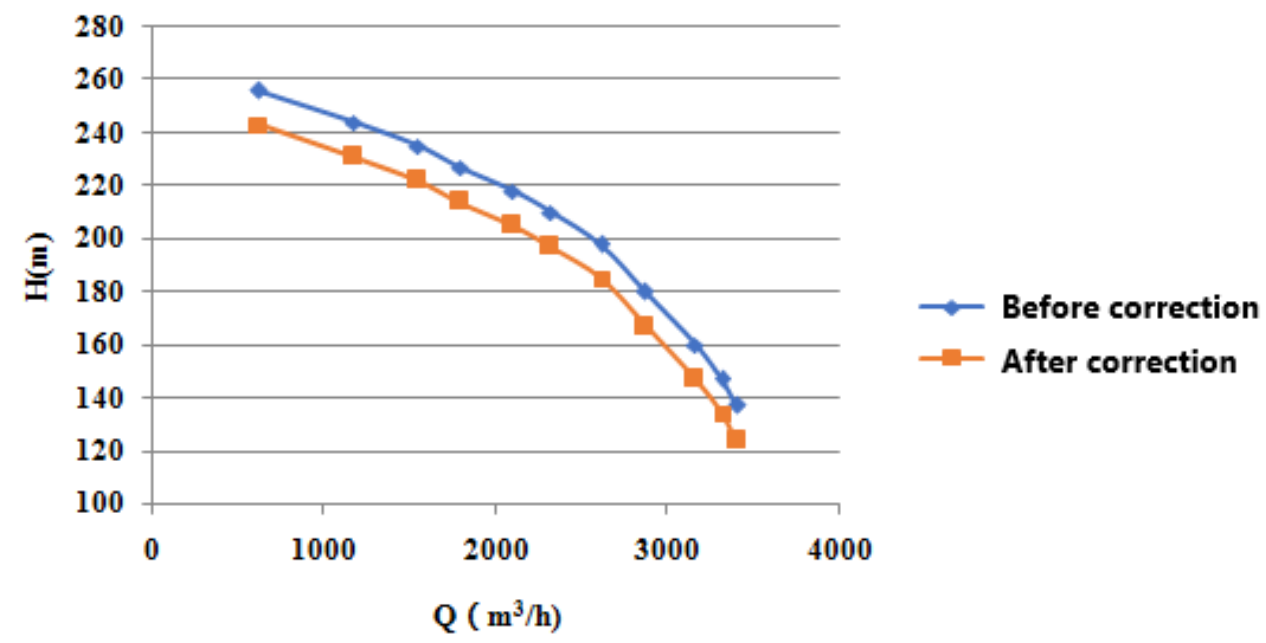

Figure 7. Comparison before and after head correction

\section{RESEARCH ON SLACK FLOW CONTROL}

Stoner pipeline simulator/(SPS) is an advanced fluid simulation application, which can simulate any existing or planned pipeline, simulate normal or abnormal conditions such as pipeline rupture, equipment failure or others, and predict the results of various control strategies. In this paper, the position of the crossing point and the pipe section under the condition of slack flow is determined efficiently and accurately by using the SPS hydraulic gradient diagram, and the response scheme of the slack flow condition under different throughput steps is simulated, which has a good guiding role for the engineering practice [2629].

\subsection{Position determination of slack flow pipe section}

With the help of SPS simulation software, the hydraulic conditions of the whole line are simulated. The possible position of the crossing point can be accurately found through the simulation of the hydraulic gradient along the route, as shown in Fig. 8 and Fig. 9.

It is known from the above that after the liquid flow crosses the peak, the sum of the potential energy depending on the natural fall of the terrain and the residual energy head after crossing the high point is greater than the sum of the friction loss of the pipe section and the converted head of the pressure set at the end point, and the slack flow condition will occur, which is the crossing point. It is determined by calculating in the following whether there is a slack flow condition under the designed throughput of China-Kazakhstan crude oil pipeline and the minimum throughput to avoid the slack flow condition. [30-32]

Combining the mileage and elevation data from 11\#station to terminal station with the tangent point position of SPS hydraulic gradient map, it can be seen that the coordinates of high point A are $(147.21 \mathrm{~km}, 568.999 \mathrm{~m})$, and the coordinates of terminal point B are (171.63km, 346.280m) (abscissa is the distance from 11\#station).

According to the basic data, the frictional loss can be calculated by selecting the corresponding formula. The comprehensive parameter friction calculation formula is adopted, i.e. Leapienzon formula. The frictional resistance calculation formula of each flow regime 


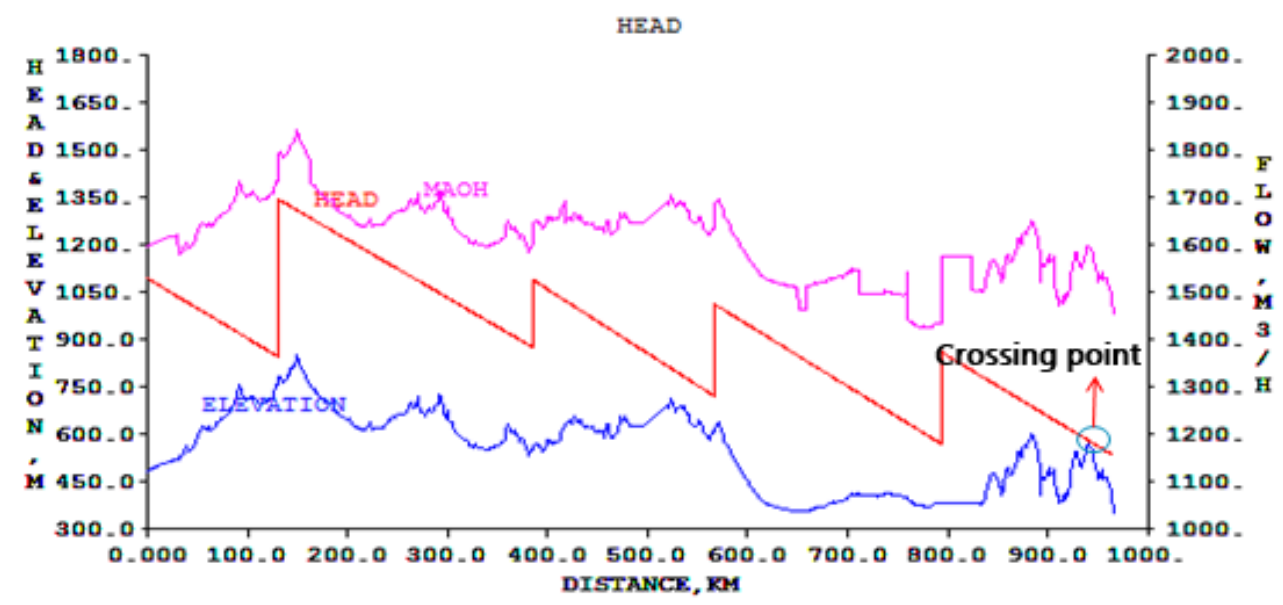

Figure 8. Hydraulic gradient along the line

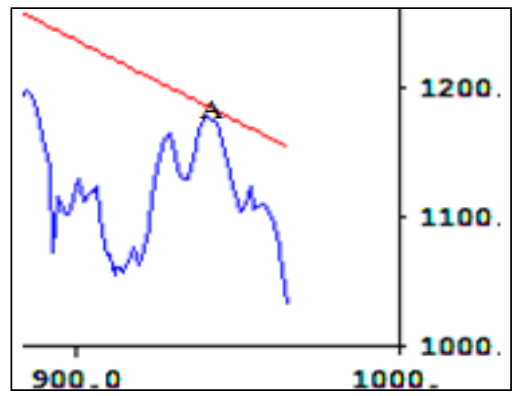

Figure 9. Partial enlarged view

Table 7. Formula for friction along the way

\begin{tabular}{lll}
\hline Flow pattern & Reynolds number range & Friction along the way (hf)
\end{tabular}

Laminar flow

Re $\leq 2000 \quad h_{f}=4.15 \frac{Q v}{D^{4}} L$

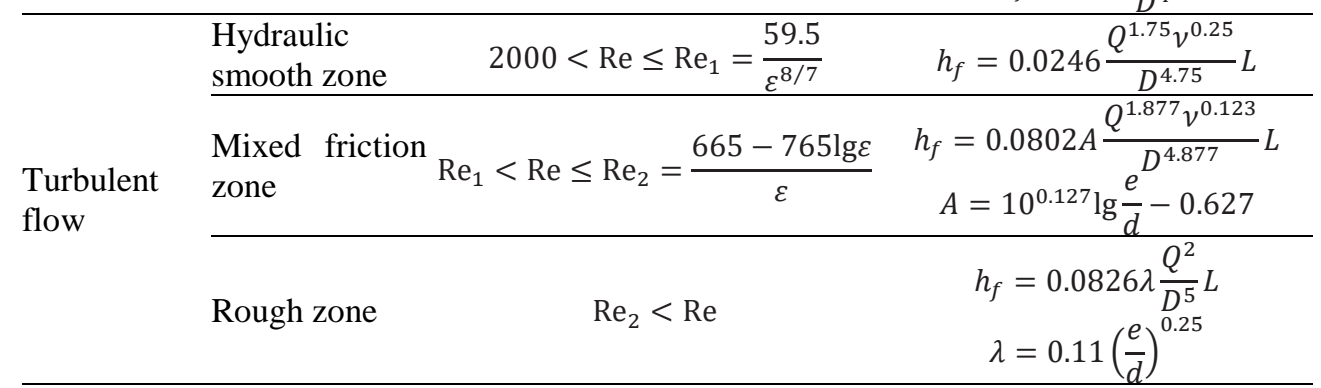

According to the calculation, the whole pipeline is in the hydraulic smooth area, so the formula of friction along the pipeline is as follows:

$$
h_{f}=0.0246 \frac{Q^{1.75} v^{0.25}}{D^{4.75}} L
$$


(1) Calculate whether there will be a slack flow condition under the designed throughput: According to the data, the frictional resistance is $86.48 \mathrm{~m}$ head, which is far less than $222.719 \mathrm{~m}$ head provided by potential energy. The friction loss cannot offset the sum of the head provided by potential energy and the residual head when crossing the high point. If the corresponding measures are not taken after the crossing point, the slack flow condition will occur, which will affect the safe operation of the pipeline.

(2) Inverse calculation of the minimum throughput to avoid slack flow condition:

Assuming that the frictional resistance along the pipeline is equal to $222.719 \mathrm{~m}$ of potential energy. By introducing the friction calculation formula along the way, the minimum throughput is $2.90 \mathrm{MMt} / \mathrm{A}$ which is much larger than the designed capacity of ChinaKazakhstan crude oil pipeline. At present, the actual throughput of China-Kazakhstan crude oil pipeline is less than the designed capacity. If no corresponding measures are taken, the slack flow condition will exist for a long time and affect the efficient and safe operation of the pipeline.

To sum up, it is very necessary to study the coping strategies of slack flow after crossing point.

\subsection{Slack flow control strategy}

In order to adapt to the needs of eliminating residual energy and reducing dynamic pressure under various working conditions, pressure control equipment with regulating capacity must be installed at the proper position of downhill pipeline (generally by-pass installation mode is adopted to pass the pig). Orifice throttling energy dissipation device and pressure regulating device are two kinds of frequently used pressure control equipment.

According to the actual situation of China-Kazakhstan crude oil pipeline, the ratchet cage axial flow pressure reducing valve produced by the Dutch Mokveld company is adopted in Alashankou metering station. The phenomenon of slack flow can be eliminated by properly controlling the inlet pressure of oil from the terminal station. Although some energy is wasted, the pipeline can be operated in a safe range. SPS simulation software can be used to calculate the critical pressure of China-Kazakhstan crude oil pipeline to avoid the slack flow condition. In SPS, the terminal station is set as flow control. Under the condition of meeting the transportation requirements, the terminal station pressure is the one under full flow condition, and it is also the critical pressure to avoid slack flow condition. When the terminal station pressure is set to be greater than the pressure, the slack flow condition can be avoided. [3637]. The following is an example of $2254.4 \mathrm{~m}^{3} / \mathrm{h}(46500 \mathrm{~T} / \mathrm{D})$ to simulate the critical pressure to avoid the condition of slack flow:

(1) Firstly, the terminal station is set as flow control

Set the terminal station as flow control, that is, SPT is flow, and fill in the throughput scheme to be tested, that is, the set value of SQ is $2254.4 \mathrm{~m}^{3} / \mathrm{h}(46500 \mathrm{~T} / \mathrm{D})$. 


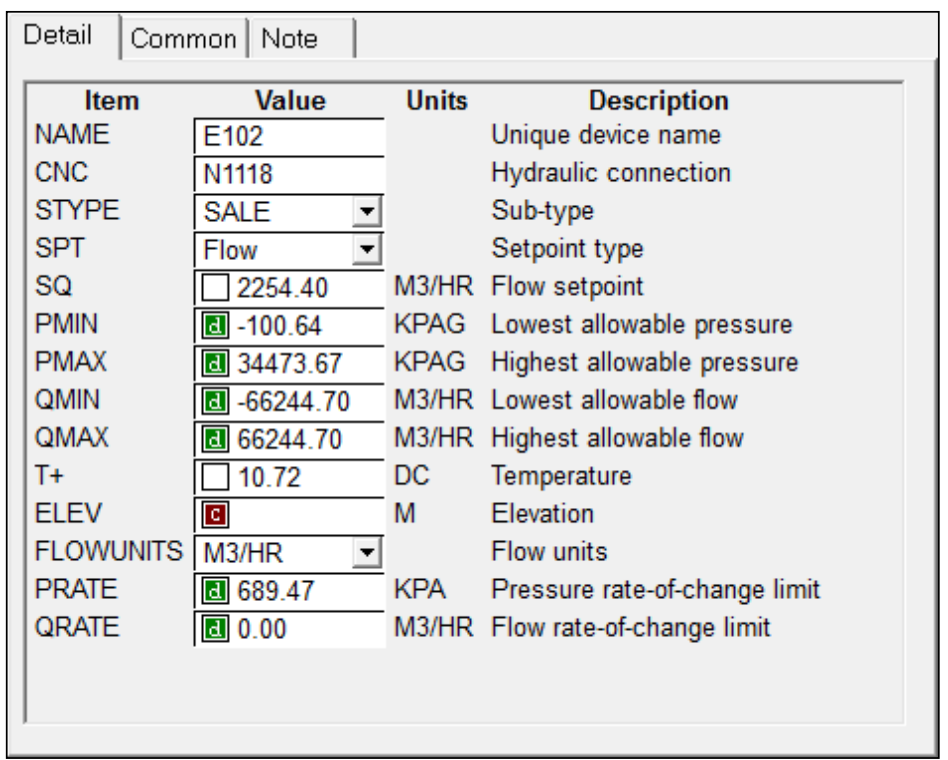

Figure 10. Flow control of terminal station

(2) According to the hydraulic gradient diagram to determine the optimal pump scheme The green curve in the figure is the flow rate (STANDARD.FLOW). The blue curve is elevation variation (ELEVATION), and the red curve is hydraulic gradient (HEAD):

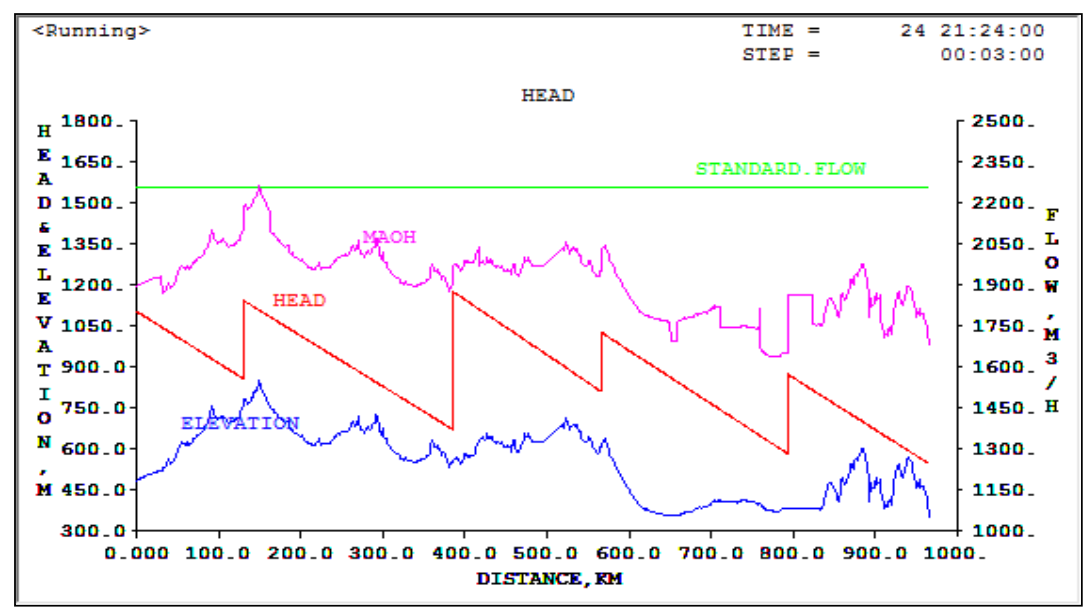

Figure 11. Hydraulic gradient along the way

(3) Control the high point pressure to $0.2 \mathrm{MPa}$, and read the critical pressure combined with the end point pressure change curve and the end point pressure change.

SPS can calculate the pressure value along the way. The critical pressure (high point pressure is $0.2 \mathrm{MPa}$ ) which can avoid under flow condition can be accurately read by reading terminal station pressure versus time curve and terminal station pressure real-time change graph in SPS, as shown in Fig. 12 and Fig. 13: 


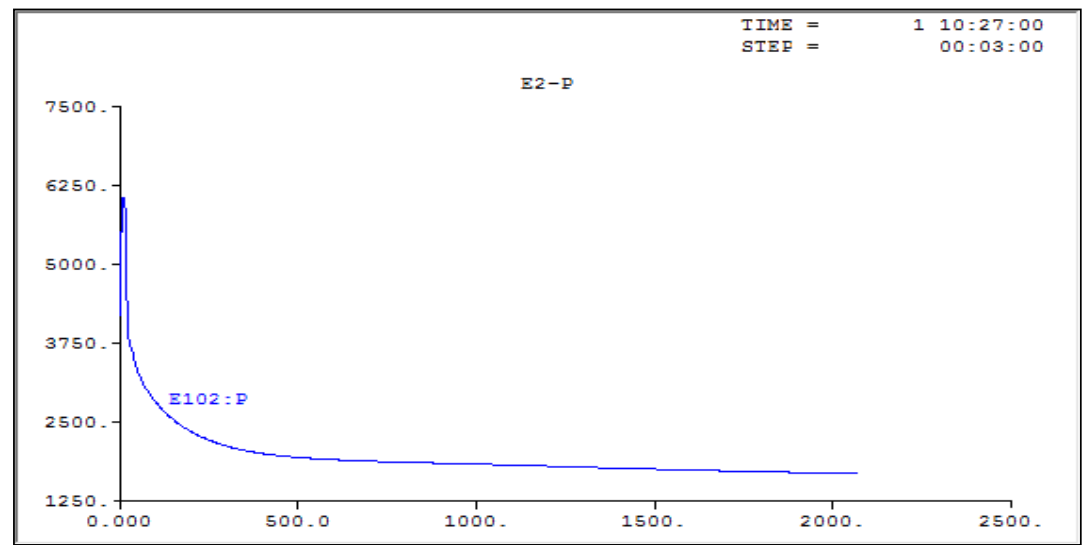

Figure 12. Pressure curve of terminal station with time

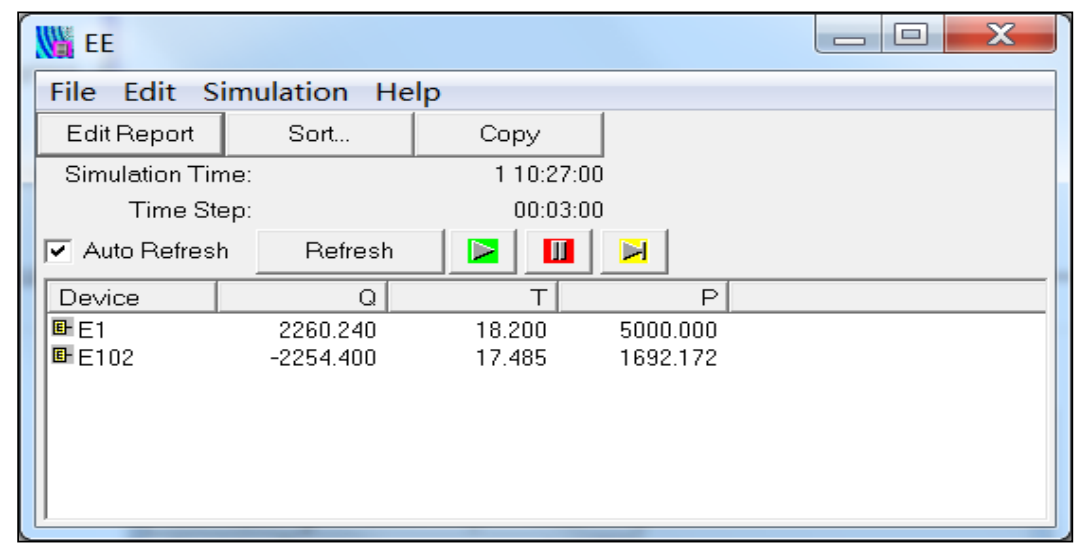

Figure 13. Real-time variation of end point pressure

As shown in Fig. 12 and Fig. 13, under the working condition of 2254.4m3/h, the critical pressure to avoid slack flow condition is $1692.172 \mathrm{kpa}$. If the set value of oil pressure at the terminal station is set higher than the pressure value, the occurrence of slack flow condition can be avoided.

In order to avoid the occurrence of slack flow condition, the critical pressure value under different throughput steps is tested, and the terminal station pressure is set to be greater than the pressure value under corresponding throughput conditions. The control pressure test results under different throughput steps are shown in the table below [38-39]: 
Table 8. Pressure control table under different throughput steps

\begin{tabular}{lllllll}
\hline \multirow{2}{*}{ Throughput } & $\left(\mathbf{m}^{\mathbf{3}} / \mathbf{h}\right)$ & 1274.5 & 1519.61 & 1617.65 & 1715.69 & 1813.73 \\
& $(\mathbf{1 0 4 t} / \mathbf{d})$ & 2.6 & 3.1 & 3.3 & 3.5 & 3.7 \\
\hline \multicolumn{2}{c}{ Critical pressure (MPa) } & 1.92 & 1.879 & 1.857 & 1.835 & 1.812 \\
\hline \multirow{2}{*}{ Throughput } & $\left(\mathbf{m}^{\mathbf{3}} / \mathbf{h}\right)$ & 1911.76 & 2009.8 & 2107.84 & 2205.88 & 2303.92 \\
& $\mathbf{( 1 0 4 t / d )}$ & 3.9 & 4.1 & 4.3 & 4.5 & 4.7 \\
\hline Critical pressure (MPa) & 1.787 & 1.761 & 1.734 & 1.706 & 1.678 \\
\hline
\end{tabular}

3.3. Development of calculation program for critical pressure of slack flow In order to calculate the pressure control value to avoid slack flow under different throughput steps, a program for calculating the critical pressure of slack flow is developed to calculate the control pressure of slack flow under any throughput and different conditions.

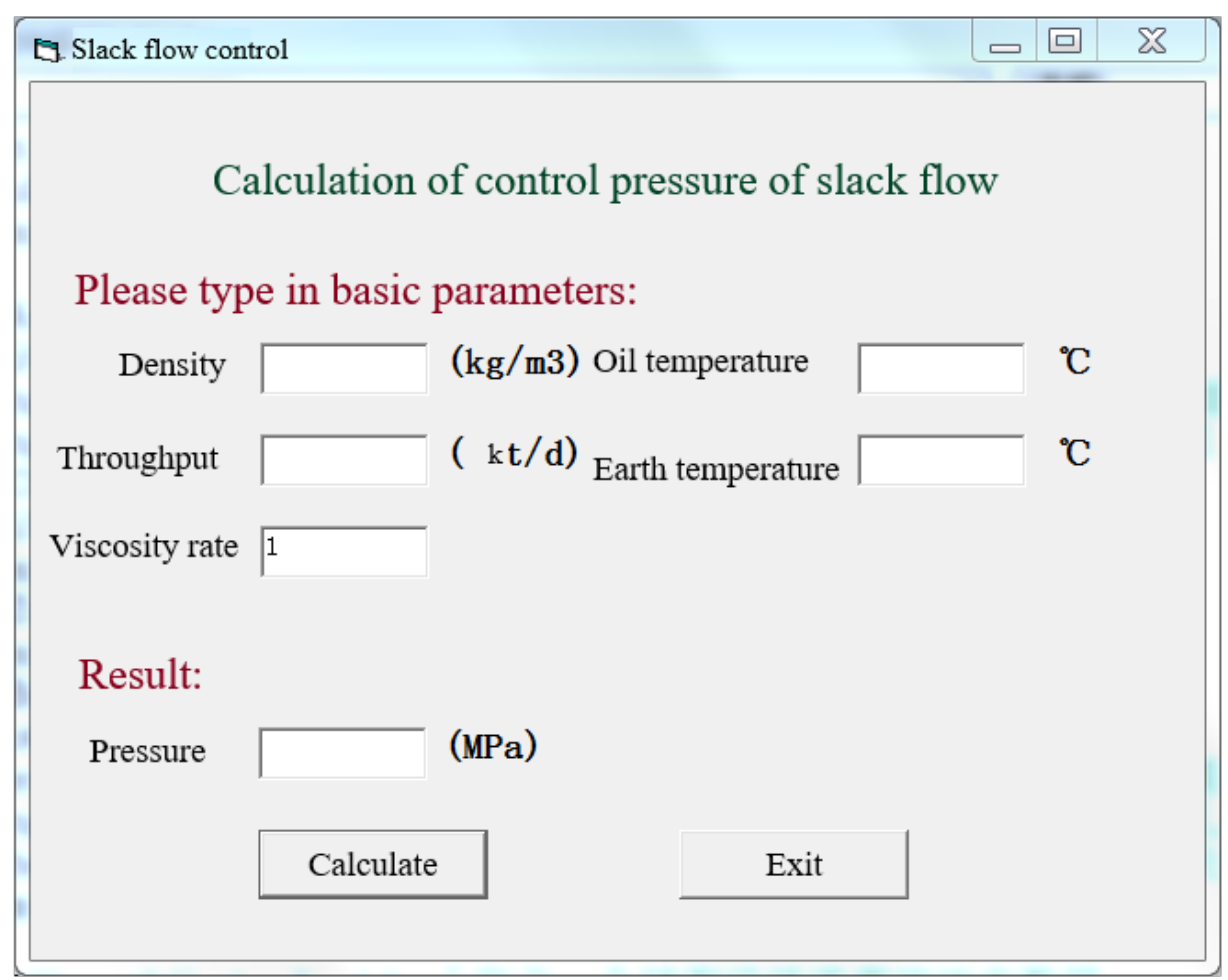

Figure 14. Interface of slack flow calculation program 
1. Parameter input:

- Density: density at $20^{\circ} \mathrm{C}, \mathrm{kg} / \mathrm{m}^{3}$;

- $\quad$ Oil temperature: the oil temperature here should be the one at the high point (crossing point). Considering the small oil temperature change and the short distance from the high point to the terminal station, it can be filled in according to the oil temperature change rule from 11 \# station to terminal station; generally, slightly higher or lower than the oil temperature at the inlet station, that is, if the oil temperature from 11 \# station to the terminal station is in a descending process, the high point oil temperature is slightly higher, if the oil temperature from 11 \# station to terminal station rises, the input high point oil temperature is slightly lower than that of the terminal station;

- Throughput: is the daily one in kt / D, which can be input according to the actual on-site throughput.

- Earth temperature: is the earth temperature of the pipe section of the terminal station;

- The viscosity ratio: it can be adjusted up and down according to the change of oil properties.

(2) Result output

The running effect after inputting operation parameters is shown in Figure 15.

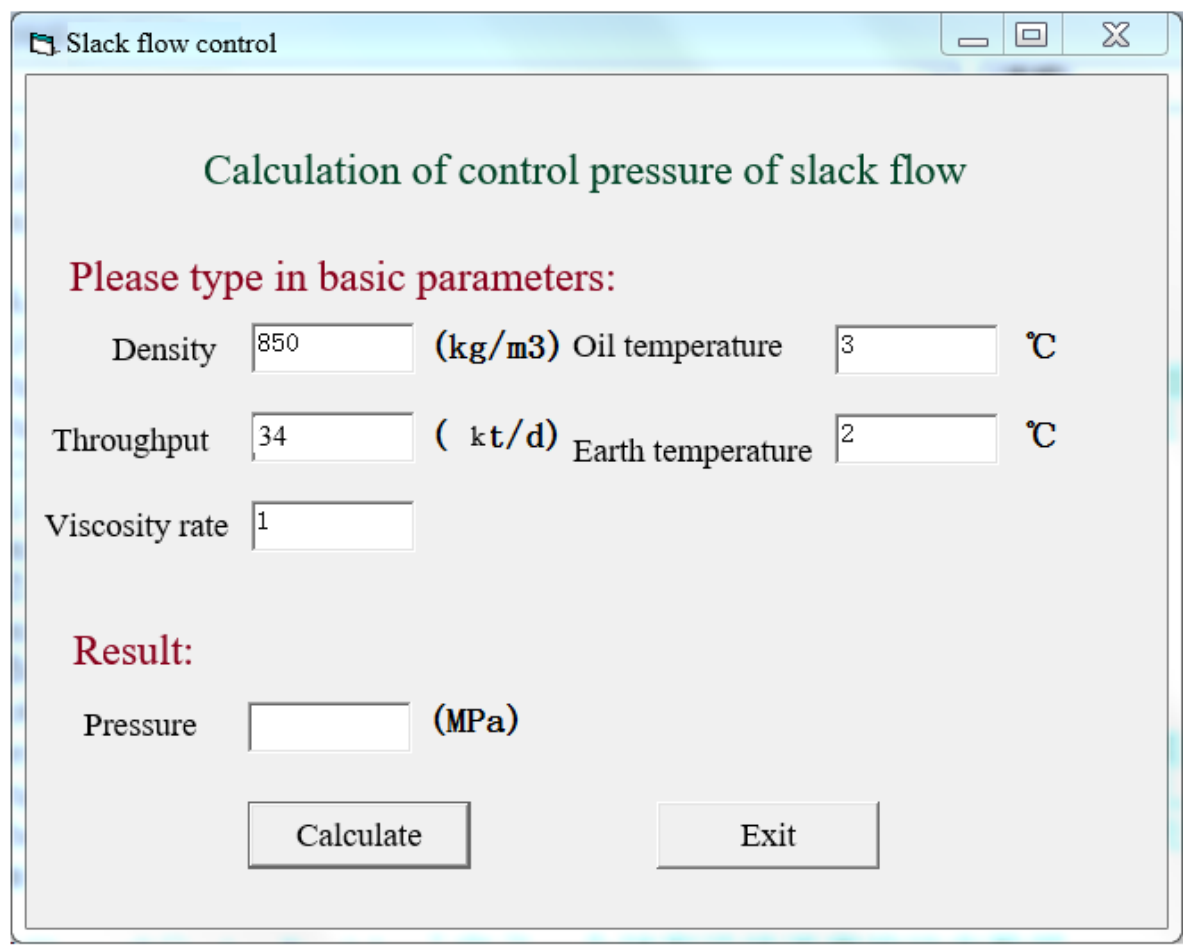

Figure 15. Schematic diagram of operation effect 
(3) Comparative verification

In order to test the accuracy of the slack flow control program, the software simulation results are compared with the SPS simulation results to verify the accuracy of the developed software. Take $1274.5 \mathrm{~m} 3 / \mathrm{h}(26000 \mathrm{t} / \mathrm{h})$ condition as an example:

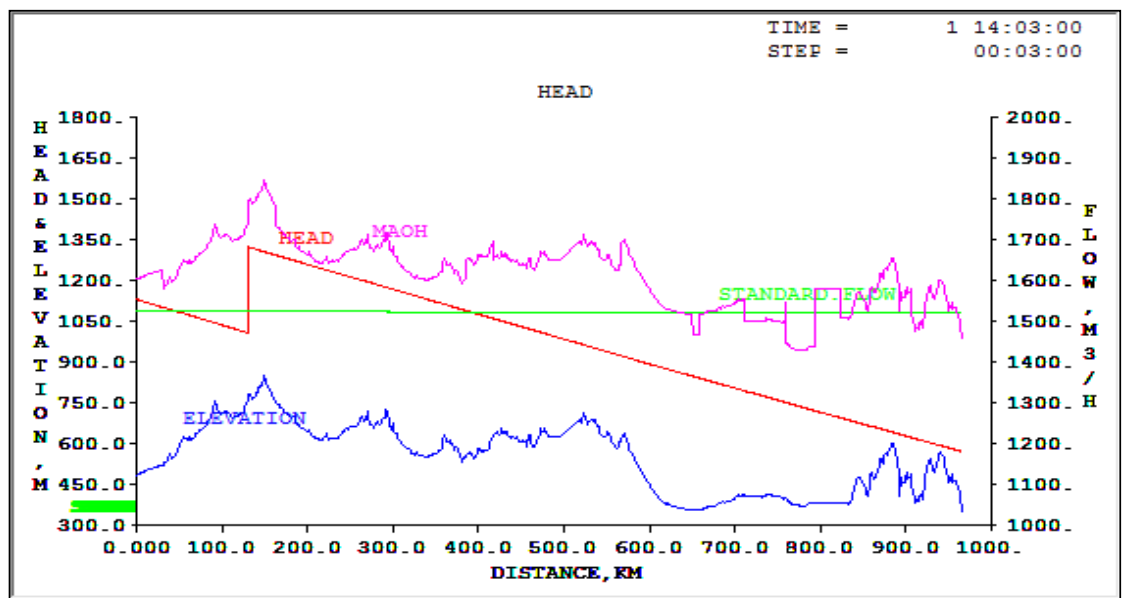

Figure 16. SPS hydraulic gradient with throughput of $1274.5\left(\mathrm{~m}^{3} / \mathrm{h}\right)$

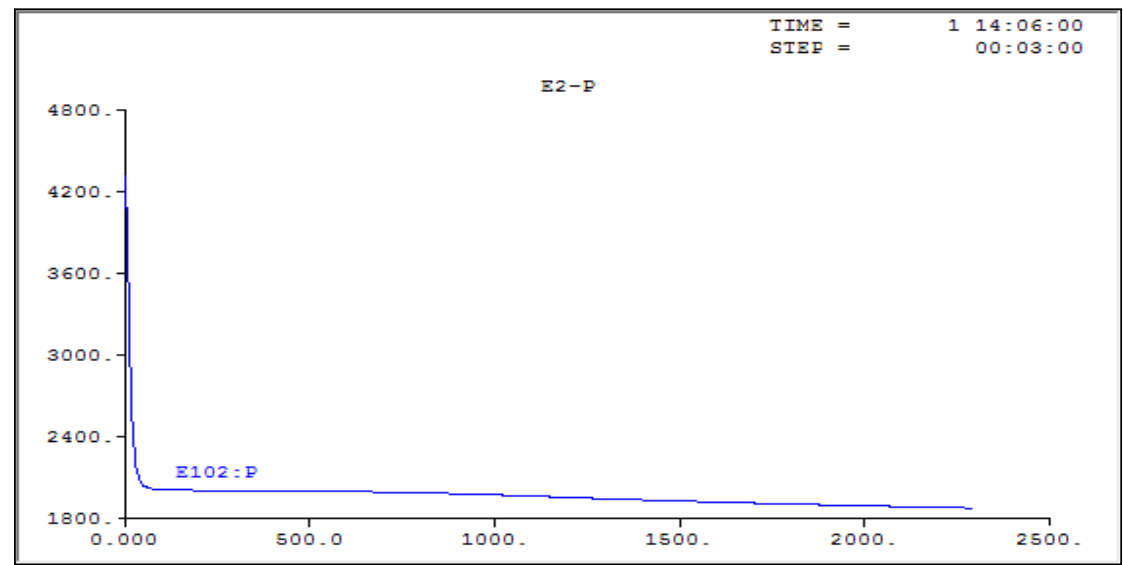

Figure 17. Pressure change curve of SPS terminal point with throughput of 1274.5 $\left(\mathrm{m}^{3} / \mathrm{h}\right)$ 


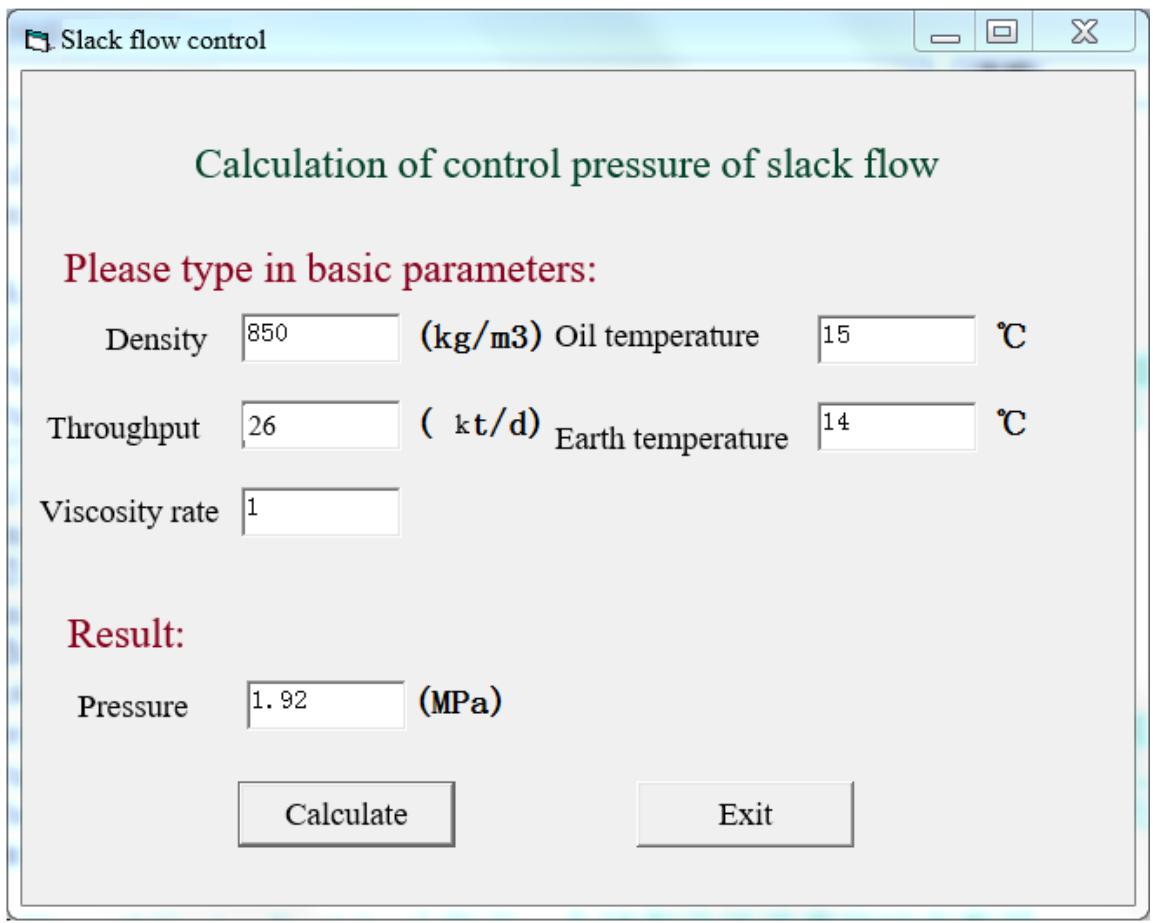

Figure 18. Calculation results of optimization software for throughput $1274.5\left(\mathrm{~m}^{3} / \mathrm{h}\right)$

The result of SPS simulation is $1.926 \mathrm{MPa}$, and the calculation result of optimization software is $1.92 \mathrm{MPa}$, and the error is $0.31 \%$; through comparative calculation, it is found that the relative error between the calculation result of optimized operation software and the simulation result of SPS under different throughput steps is within 3\%. Moreover, the calculation program of slack flow critical pressure can realize the calculation of critical pressure under different throughput, different environmental conditions and different physical properties of oil products. It has the advantages of strong applicability and high calculation accuracy. In the actual operation of the pipeline, the set value of terminal station pressure can be set higher than above pressure value to avoid the occurrence of slack flow condition under this throughput, to ensure the safe, efficient and stable operation of the pipeline.

\section{CONCLUSION AND INNOVATION}

In this paper, the dissatisfied flow in the pipeline is controlled by adjusting the critical pressure in the pipeline. Because the operating temperature in the pipeline does not change much, the main condition of fluid gas-liquid separation under the condition of multiple physical fields in the pipeline is that the pressure is below the saturated vapor pressure of the fluid, especially affected by the operating pressure in the pipeline.

Simulation technology is the basis of research on slack flow control strategy of ChinaKazakhstan crude oil pipeline. In this paper, the correction method of oil pump performance curve is determined to ensure the accuracy of all research basis; from the perspective of macro optimization, the control of pipeline slack flow condition is realized by studying the control value of the minimum inlet pressure at the terminal station under different throughput, so as to ensure the safe and stable operation; The specific innovation of this paper is as follows: 
(1) The physical properties of the oil for research were determined. The whole pipeline of China-Kazakhstan crude oil pipeline has the characteristics of complex oil source composition and great difference in physical properties of different oil sources. Therefore, the physical properties of actual pipeline oil are uncertain. During the period from October 19 to 24, 2019, crude oil samples were taken and physical properties tests were carried out at Alashankou metering station at the end of the pipeline. According to ISO3170, the crude oil was sampled manually for 400ml every 2 hours, 6 consecutive days. $4800 \mathrm{ml} * 6$ crude oil samples were obtained. The physical properties of crude oil are determined by testing the oil samples. From this, a series of research work was carried out.

(2) Study and formulate the calibration method of pump performance curve and complete the curve correction. By optimizing the equation fitting the pump factory characteristics, the head-flow and efficiency-flow characteristic parameter curves of the pump are fitted, and 24 pumps in the whole line are fitted; the calibration method of factory characteristic curve of oil pump is studied, and the pump performance curve is corrected by screening the steady-state historical operation data, and the pump performance calculation and curve data automatic correction software are developed. The deviation between the simulation and the actual value should not exceed $3 \%$

(3) The whole line simulation model is established. According to the actual operation situation of the whole line, the hydraulic and thermal calculation model of the pipeline is established by using SPS simulation system, and the hydraulic and thermal verification is carried out by using the field collected data, so that the relative error between the simulation result and the actual operation is within $3 \%$.

(4) The control strategy of slack flow at the high point of pipeline is studied. The potential location of slack flow in pipeline is analyzed, the boundary condition of slack flow condition is defined, the control method to avoid slack flow condition is determined, and the calculation program of slack flow control is developed.

\section{ACKNOWLEDGEMENT}

This work is supported by Heilongjiang Postdoctoral Scientific Research Development Fund. (Grant No.: LBH-Q20010).

\section{REFERENCE}

[1] Xu, P. , He, L. , Yang, D. , Zhou, S. , \& Yang, D. Blocking characteristics of high watercut crude oil in low-temperature gathering and transportation pipeline. Chemical Engineering Research and Design, 2021, (3-4).

[2] Shaik, N. B. Pedapati, S. R. Othman, A. R. Bingi, K. , \& Dzubir, F. An intelligent model to predict the life condition of crude oil pipelines using artificial neural networks. Neural Computing and Applications, 2021, (3).

[3] Mcarthur S D J, Davidson E M, Hossack J A, et al. Automating power system fault diagnosis through multi-agent system technology. Proceedings of the Hawaii International Conference on System Sciences, IEEE Computer Society, 2004:20059.1.

[4] Wang, S. Zuo, L. Li, M., Wang, Q., Xue, X., \& Liu, Q., et al. The data-driven modeling of pressure loss in multi-batch refined oil pipelines with drag reducer using long shortterm memory (lstm) network. Energies, 2021, 14.

[5] Lpg, A. Xue, H. A., Yun, L. B., Lei, W. C., Pfy, B., \& Shuang, S. A. Study on the thixotropy and structural recovery characteristics of waxy crude oil emulsion. Petroleum Science. 2021. 
kinetic parameter estimation in a trickle-bed reactor. Chinese Journal of Chemical Engineering, 2021,29, 212-220.

[7] Xu, L. Hou, L. Zhu, Z., Li, Y. , \& Wu, X. Mid-term prediction of electrical energy consumption for crude oil pipelines using a hybrid algorithm of support vector machine and genetic algorithm. Energy, 2021,222(1), 119955.

[8] Bao, Y. \& Zhang, J. Restart behavior of gelled waxy crude oil pipeline based on an elastoviscoplastic thixotropic model: a numerical study. Journal of Non-Newtonian Fluid Mechanics, 2020, 104377.

[9] Hafez, K. M. The role of a plain dent on the failure mode of a crude oil pipeline. Engineering Failure Analysis, 2021,122, 105291.

[10] Shengzhu, Zhang, Xu, Wang, Frank, Y., \& Cheng, et al. Modeling and analysis of a catastrophic oil spill and vapor cloud explosion in a confined space upon oil pipeline leaking. Petroleum Science, 2020, v.17 (02), 280-290.

[11]Wang, Y., Magda, J., Venkatesan, R., Sambath, K., \& Deo, M. Experimental and theoretical investigations of waxy crude oil in steady and transient pipe flows. Industrial And Engineering Chemistry Research, 2020, 59(30), 13783-13798.

[12]Yang, W. Q., Stott, A. L., \& Beck, M. S. Development of capacitance tomographic imaging systems for oil pipeline measurements. Review of Scientific Instruments,1995, 66(8), 4326-4332.

[13] Sepehr, H., Nikrityuk, P., Breakey, D. , \& Sanders, R. S. Numerical study of crude oil batch mixing in a long channel. Petroleum Science, 2019,16(1), 187-198.

[14] Al-Busaidi, Z., Baawain, M., Sana, A., Ebrahimi, A., \& Omidvarborna, H. Sustainable risk-based analysis towards remediation of an aquifer impacted by crude oil spills. Journal of Environmental Management, 2019,247(Oct.1), 333-341.

[15] Niermann, M., Druenert, S. , Kaltschmitt, M. , \& Bonhoff, K. Liquid organic hydrogen carriers (lohcs) - techno-economic analysis of lohcs in a defined process chain. Energy \& Environmental Science, 2019,12(1), 290-507.

[16] Liu, Y., Cheng, Q. , Gan, Y. , Wang, Y. , Li, Z. , \& J Zhao. Multi-objective optimization of energy consumption in crude oil pipeline transportation system operation based on exergy loss analysis. Neurocomputing, 2019, 332(MAR.7), 100-110.

[17] Yang, S. , Xi, W. , Jin, H. , \& Wu, Q. Pyrosequencing investigation into the bacterial community in permafrost soils along the china-russia crude oil pipeline (crcop). PLoS ONE, 2012, 7(12), e52730.

[18] Magda, J. J. , El-Gendy, H. , Oh, K. , MD Deo, Montesi, A. , \& Venkatesan, R. Timedependent rheology of a model waxy crude oil with relevance to gelled pipeline restart. Energy \& fuels, 2009,23(2), 1311-1315.

[19] Arora, H. , Hooper, P. , Del Linz, P. , Yang, H. , Chen, S. , \& Dear, J. Modelling the behaviour of composite sandwich structures when subject to air-blast loading. International Journal of Multiphysics, 2012, 6(3), 199-218.

[20] Singh, P. , Fogler, H. S. , \& Nagarajan, N. Prediction of the wax content of the incipient wax-oil gel in a pipeline: an application of the controlled-stress rheometer. Journal of Rheology, 1999,43(6), 1437-1459.

[21] Abedi, S. S. , Abdolmaleki, A. , \& Adibi, N. Failure analysis of scc and srb induced cracking of a transmission oil products pipeline - science direct. Engineering Failure Analysis, 2007,14( 1), 250-261. 
[22] Nixon, J. , \& Macinnes, K. L. Application of pipe temperature simulator for norman wells oil pipeline. Canadian Geotechnical Journal, 2011,33(1), 140-149.

[23] Singh, S. , Sarma, P. M. , \& Lal, B. Biohydrogen production by thermoanaerobacterium thermosaccharolyticum teri s7 from oil reservoir flow pipeline. International Journal of Hydrogen Energy, 2014,39(9), 4206-4214.

[24] Wu, Z. , Barosh, P. J. , Wang, L. , Hu, D. , \& Wei, W. Numerical modeling of stress and strain associated with the bending of an oil pipeline by a migrating pingo in the permafrost region of the northern tibetan plateau. Engineering Geology, 2008,96(1-2), 62-77.

[25] Hennessy, A. J. , Neville, A. , \& Roberts, K. J. An examination of additive-mediated wax nucleation in oil pipeline environments. Journal of Crystal Growth, 1999,198-199(1), 830-837.

[26] MD Chapetti, Otegui, J. L. , \& Motylicki, J. Fatigue assessment of an electrical resistance welded oil pipeline. International Journal of Fatigue, 2002,24(1), 21-28.

[27] Yan, S. Z. , \& Chyan, L. S. Performance enhancement of botdr fiber optic sensor for oil and gas pipeline monitoring. Optical Fiber Technology, 2010, 16(2), 100-109.

[28]Zhu, H. , Lin, P. , \& Pan, Q. A cfd (computational fluid dynamic) simulation for oil leakage from damaged submarine pipeline. Energy, 2014, 64, 887-899.

[29]Lei, H. , Huang, Z. , Liang, W. , Mao, Y. , \& Que, P. W. Ultrasonic pig for submarine oil pipeline corrosion inspection. Russian Journal of Nondestructive Testing, 2009, 45(4), 285-291.

[30]Xu, P. , He, L. , Yang, D. , Zhou, S. , \& Yang, D. Blocking characteristics of high watercut crude oil in low-temperature gathering and transportation pipeline. Chemical Engineering Research and Design. 2021, (3-4).

[31]Bao, Y. , Zhang, J. , Wang, X. , \& Liu, W. Effect of pre-shear on structural behavior and pipeline restart of gelled waxy crude oil. Rsc Advances, 2016, 6(84), 80529-80540.

[32] Gan, Y. , Cheng, Q. , Sun, W. , Gao, W. , Liu, X. , \& Liu, Y. The stability criterion model and stability analysis of waxy crude oil pipeline transportation system based on excess entropy production. Journal of Thermal Science, 2018,27(06), 1-14.

[33] Mendoza-Cantu, A., Heydrich, S. C. , Cervantes, I. S. , \& Orozco, O. O. Identification of environmentally vulnerable areas with priority for prevention and management of pipeline crude oil spills. Journal of Environmental Management, 2011,92(7), 1706-1713.

[34]Roehner, R. M., Fletcher, J. V. , Hanson, F. V. , \& Dahdah, N. F. Comparative compositional study of crude oil solids from the transalaska pipeline system using hightemperature gas chromatography. Energy \& Fuels, 2002,16(1), 211-217.

[35]Azevedo, C. Failure analysis of a crude oil pipeline. Engineering Failure Analysis, 2007,14(6), 978-994.

[36]Yanhu, M. , Guoyu, L. , Wei, M. , Zhengmin, S. , Zhiwei, Z. , \& Wang, F. Rapid permafrost thaw induced by heat loss from a buried warm-oil pipeline and a new mitigation measure combining seasonal air-cooled embankment and pipe insulation. Energy, 2020,203.

[37]Hafez, K. M. The role of a plain dent on the failure mode of a crude oil pipeline. Engineering Failure Analysis, 2021,122, 105291. 
[38]Xu, L., Hou, L., Zhu, Z., Li, Y., \& Wu, X. Mid-term prediction of electrical energy consumption for crude oil pipelines using a hybrid algorithm of support vector machine and genetic algorithm. Energy, 2021, 222(1), 119955.

[39]Wang, Q. , Ai, M., Shi, W. , Lyu, Y., \& Yu, W. Study on corrosion mechanism and its influencing factors of a short distance intermittent crude oil transmission and distribution pipeline. Engineering Failure Analysis, 2020,118(3), 104892. 
